\title{
Risk Management-An Analytical Study
}

\author{
Ms. Pooja Kungwani \\ Lecturer, Department of management studies, Takshshila Institute Of Engineering \& Technology, Jabalpur
}

\begin{abstract}
In finance, risk is the probability that an investment's actual return will be different than expected. This includes the possibility of losing some or all of the original investment. A fundamental idea in finance is the relationship between risk and return. The greater the potential return one might seek, the greater the risk that one generally assumes.

Risk management is an activity which integrates recognition of risk, risk assessment, developing strategies to manage it, and mitigation of risk using managerial resources. Some traditional risk managements are focused on risks stemming from physical or legal causes (e.g. natural disasters or fires, accidents, death). Financial risk management, on the other hand, focuses on risks that can be managed using traded financial instruments. Objective of risk management is to reduce different risks related to a pre-selected domain to an acceptable. It may refer to numerous types of threats caused by environment, technology, humans, organizations and politics. The paper describes the different steps in the risk management process which methods are used in the different steps, and provides some examples for risk and safety management.

The financial risk should be minimized by analyzing the capital structure of the company. If the debt equity ratio is higher, the investor should have a sense of caution. Along with the capital structure analysis, he should also take into account of the interest payment. In a boom period, the investor can select a highly levered company but not in a recession.
\end{abstract}

Keywords: Financial risk management, Investment, Management, Return, Risk

\subsection{Risk}

\section{Introduction}

Risk is the potential of losing something of value, weighed against the potential to gain something of value. Values (such as physical health, social status, emotional well being or financial wealth) can be gained or lost when taking risk resulting from a given action, activity and/or inaction, foreseen or unforeseen. Risk can also be defined as the intentional interaction with uncertainty.

\subsection{Financial Risk}

In finance, risk is the probability that an investment's actual return will be different than expected. This includes the possibility of losing some or all of the original investment. A fundamental idea in finance is the relationship between risk and return. The greater the potential return one might seek, the greater the risk that one generally assumes. A free market reflects this principle in the pricing of an instrument: strong demand for a safer instrument drives its price higher (and its return proportionately lower), while weak demand for a riskier instrument drives its price lower (and its potential return thereby higher). For example, a zero-risk investment, such as a U.S. Treasury security, has a low rate of return, while a stock in a start-up has the potential to make an investor very wealthy, but also the potential to lose one's entire investment. Certaintypes of risk are easier to quantify than others. To the extent that risk is quantifiable, it is generally calculated as the standard deviation on an investment's average return.

The possibility that shareholders will lose money when they invest in a company that has debt, if the company's cash flow proves inadequate to meet its financial obligations. When a company uses debt financing, its creditors will be repaid before its shareholders if the company becomes insolvent. Financial risk also refers to the possibility of a corporation or government defaulting on its bonds, which would cause those bondholders to lose money.

\subsection{Financial Risk Management: A Selective History}

No discussion of financial risk management is complete without a brief look at financial market history. Although this history is by no means complete, it illustrates events and highlights of the past several hundred years.

\subsubsection{Early Markets}

Financial derivatives and markets are often considered to be modern developments, but in many cases they are not. The earliest trading involved commodities, since they are very important to human existence. Long 
before industrial development, informal commodities markets operated to facilitate the buying and selling of products. Marketplaces have existed in small villages and larger cities for centuries, allowing farmers to trade their products for other items of value.

These marketplaces are the predecessors of modern exchanges. The later development of formalized futures markets enabled producers and buyers to guarantee a price for sales and purchases. The ability to trade product and guarantee a price was particularly important in marketswhere products had limited life, or where products were too bulky to transport to market often.

Forward contracts were used by Flemish traders at medieval trade fairs as early as the twelfth century, where letters de faire were used to specify future delivery. Other reports of contractual agreements date back to Phoenician times. Futures contracts also facilitated trading in prized tulip bulbs in seventeenth-century Amsterdam during the infamous tulip mania era.

In seventeenth-century Japan, rice was an important commodity. As growers began to trade rice tickets for cash, a secondary market began to flourish. The Dojima rice futures market was established in the commerce center of Osaka in 1688 with 1,300 registered rice traders.

Rice dealers could sell futures in advance of a harvest in anticipation of lower prices, or alternatively buy rice futures contracts if it looked as though the harvest might be poor and prices high. Rice tickets represented either warehoused rice or rice that would be harvested in thefuture. Trading at the Dojima market was accompanied by a slow-burning rope in a box suspended from the roof. The day's trading ended when the rope stopped burning. The day's trading might be canceled, however, if there were no trading price when the rope stopped burning or if it expired early.

\subsubsection{North American Developments}

In North America, development of futures markets is also closely tied to agricultural markets, in particular the grain markets of the nineteenth century. Volatility in the price of grain made business challenging for both growers and merchant buyers. The Chicago Board of Trade (CBOT), formed in 1848, was the first organized futures exchange in the United States. Its business was non-standardized grain forward contracts. Without a central clearing organization, however, some participants defaulted on their contracts, leaving others unhedged. In response, the CBOT developed futures contracts with standardized terms and the requirement of a performance bond in 1865 .

These were the first North American futures contracts. The contracts permitted farmers to fix a price for their grain sales in advance of delivery on a standardized basis. For the better part of a century, North American futures trading revolved around the grain industry, where large-scale production and consumption, combined with expense of transport and storage, made grain an ideal futures market commodity.

\subsubsection{Turbulence in Financial Markets}

In the 1970s, turbulence in world financial markets resulted in several important developments. Regional war and conflict, persistent high interest rates and inflation, weak equities markets, and agricultural crop failures produced major price instability. Amid this volatility came the introduction of floating exchange rates. Shortly after the United States ended gold convertibility of the U.S. dollar, the Bretton Woods agreement effectively ended and the currencies of major industrial countries moved to floating rates. Although the currency market is a virtual one, it is the largest market, and London remains the most important center for foreign exchange trading. Trading in interest rate futures began in the 1970s, reflecting the increasingly volatile markets. The New York Mercantile Exchange (NYMEX) introduced the first energy futures contract in 1978 with heating oil futures. These contracts provided a way for hedgers to manage price risk. Other developments include the establishment of the Commodity Futures Trading Commission.

\subsubsection{Automation and Growth}

The first automated exchange began not in New York or in London but at the International Futures Exchange in Bermuda in 1984. Despite its attractive location and the foresight to automate, the exchange did not survive. However, for exchanges today, automation is often a key to survival. New resources are making their way into trading and electronic order matching systems, improving efficiency and reducing trading costs. Some exchanges are entirely virtual, replacing a physical trading floor with interconnected traders all over the world. In October 1987, financial markets were tested in a massive equity market decline, most of which took place over a couple of days. Somemajor exchanges suffered single-day declines of more than 20 percent. Futures trading volumes skyrocketed and central banks pumped liquidity into the market, sending interest rates lower. At the CBOT, futures trading volumes were three times that of the New York Stock Exchange. Later, some observers suggested that the futures markets had contributed to the panic by spooking investors. Exchanges subsequently implemented new price limits and tightened existing ones. Some traders credit leveraged futures traders with the eleventh-hour rebound in stock prices. The rally that began in the futures pits slowly spread to 
other markets, and depth and liquidity returned. The lessons of 1987 were not lost on regulators and central banks. The financial market turbulence and events highlighted serious vulnerabilities in the financial system and concerns about systemic risk. In many cases, developments have taken years to coordinate internationally but have brought lasting impact.

\subsubsection{New Era Finance}

The 1990s brought the development of new derivatives products, such as weather and catastrophe contracts, as well as a broader acceptance of their use. Increased use of value-at-risk and similar tools for risk management improved risk management dialogue and methodologies.

Some spectacular losses punctuated the decade, including the fall of venerable Barings Bank, and major losses at Orange County (California), Daiwa Bank, and Long Term Capital Management. Nolonger were derivatives losses big news. In the new era of finance, the newsworthy losses were denominated in billions, rather than millions, of dollars. In 1999, a new European currency, the euro,was adopted by Austria, Belgium, Finland, France, Germany, Ireland, Italy, Luxembourg, theNetherlands, Portugal, and Spain, and two years later, Greece. The move to a common currency significantly reduced foreign exchange risk for organizations doing business in Europe as compared with managing a dozen different currencies, and it sparked a wave of bank consolidations. As the long equities bull market that had sustained through much of the previous decade lost steam, technology stocks reached a final spectacular top in 2000. Subsequent declines for some equities were worse than those of the post-1929 market, and the corporate failures that followed the boom made history. Shortly thereafter, the terrorist attacks of September 11, 2001 changed many perspectives on risk. Precious metals and energy commodities became increasingly attractivein an increasingly unsettled geopolitical environment. New frontiers in the evolution of financial risk management include new risk modeling capabilities and trading in derivatives such as weather, environmental (pollution) credits, and economic indicators.

\subsection{Literature Review}

By Francis X. Diebold and Anthony M. Santomero titled Financial Risk Management In Volatile Global Environment (October 1999) University of Pennsylvania-

Recent events in global capital markets have brought new attention to the risks of financial trading. Risk managers need continuously to improve their assessment of risk, so too do senior executives need to improve their assessment of risk tolerance. In the recent episode, senior management may have been made complacent by the long-running boom in the global marketplace. With trading risk contributing an increasing share of bank profits, they may have both underestimated risk and overestimated their willingness to bear the consequences.

The failure to address these two issues would be a mistake. It will lead the industry to a continuation of surprises in reported trading results and could lead to loss of confidence in the system itself. Concerns over the latter could cause pundits to call for regulatory change, added disclosure, or at the very least, greater oversight.

\subsection{Origin of Financial Risk}

Financial risk arises through countless transactions of a financial nature, including sales and purchases, investments and loans, and various other business activities. It can arise as a result of legal transactions, new projects, mergers and acquisitions, debt financing, the energy component ofcosts, or through the activities of management, stakeholders, competitors, foreign governments, or weather. When financial prices change dramatically, it can increase costs, reduce revenues, or otherwise adversely impact the profitability of an organization. Financial fluctuations may make it more difficult to plan and budget, price goods and services, and allocate capital.

The type of financial risk/credit risk are depicted and explained below-

\section{Financial Risk / Credit Risk}

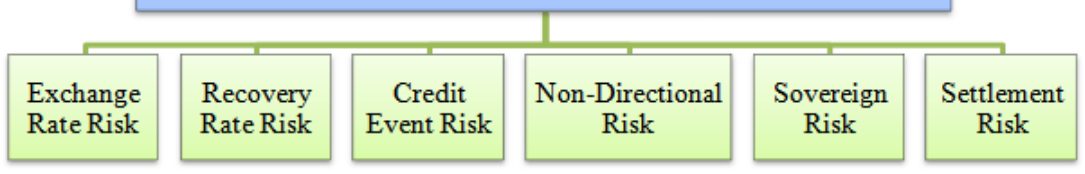

Exchange rate risk is also called as exposure rate risk. It is a form of financial risk that arises from a potential change seen in the exchange rate of one country's currency in relation to another country's currency and vice-versa. For e.g. investors or businesses face an exchange rate risk either when they have assets or operations across national borders, or if they have loans or borrowings in a foreign currency. 
Recovery rate risk is an often neglected aspect of a credit risk analysis. The recovery rate is normally needed to be evaluated. For e.g. the expected recovery rate of the funds tendered (given) as a loan to the customers by banks, non-banking financial companies (NBFC), etc. Sovereign risk is the risk associated with the government. In such a risk, government is unable to meet its loan obligations, reneging (to break a promise) on loans it guarantees, etc. Settlement risk is the risk when counterparty does not deliver a security or its value in cash as per the agreement of trade or business.

\subsection{Risk Management}

Risk management is an important part of planning for businesses. The process of risk management is designed to reduce or eliminate the risk of certain kinds of events happening or having an impact on the business.

Risk management is a process for identifying, assessing, and prioritizing risks of different kinds. Once the risks are identified, the risk manager will create a plan to minimize or eliminate the impact of negative events. A variety of strategies is available, depending on the type of risk and the type of business.

\subsection{Financial Risk Management}

Financial risk management is a process to deal with the uncertainties resulting from financial markets. It involves assessing the financial risks facing an organization and developing management strategies consistent with internal priorities and policies. Addressing financial risks proactively may provide an organization with a competitive advantage. It also ensures that management, operational staff, stakeholders, and the board of directors are in agreement on key issues of risk.

There are three main sources of financial risk:

1. Financial risks arising from an organization's exposure to changes in market prices, such as interest rates, exchange rates, and commodity prices

2. Financial risks arising from the actions of, and transactions with, other organizations such as vendors, customers, and counterparties in derivatives transactions

3. Financial risks resulting from internal actions or failures of the organization, particularly people, processes, and systems.

\subsection{Reasons for manage Financial Risk}

\section{Main Thrust Of The Paper}

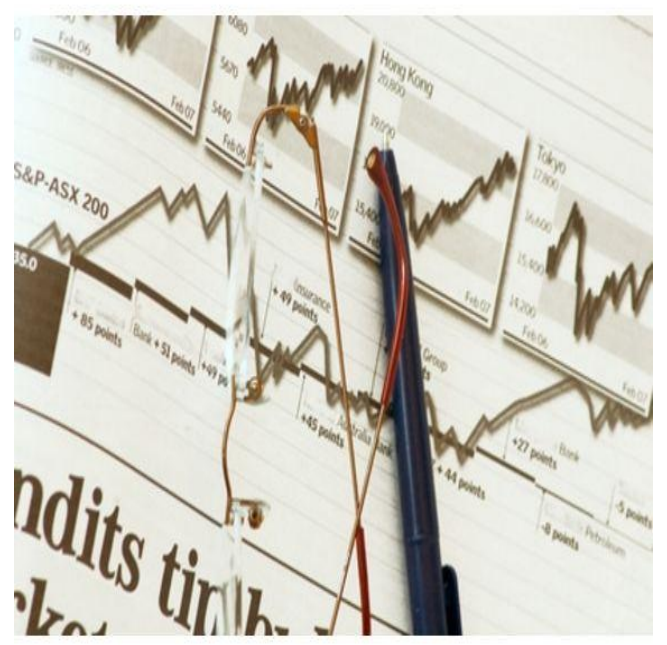

The following reasons are offered by financial economists as good reasons for risk management:-

1.Risk management can reduce the costs of financial distress and bankruptcy.

2.Risk management can be used to lower the firm's expected tax payments.

3.Risk management can be used to lower the payments demanded by a wide range of corporate stakeholders and reduce the risks of concentrated ownership in tightly held firms.

4.Risk management can be used to align the interests of management with those of the owners of the company.

5.Risk management can be used to assist firms in developing financial plans and funding programs. 


\subsection{Some Important Steps To Reduce Financial Risk}

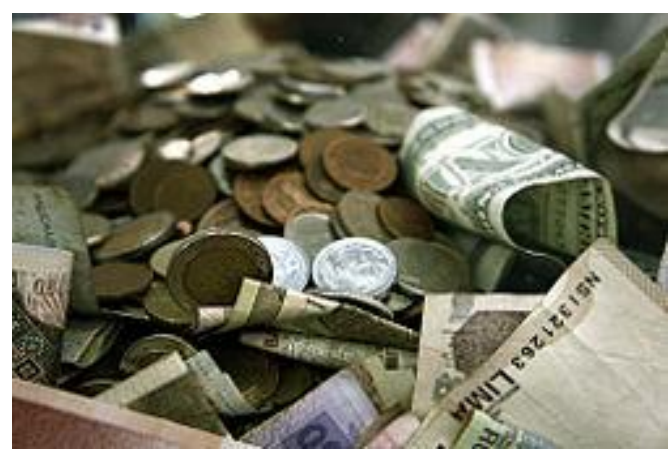

Investing, by its very nature, carries with it different types of risk. Because of changes in interest rates, inflation rates, currency exchange rates, and managerial differences between companies, one will always face the risk that an investment will lose one's money or that it will grow much more slowly than expected. To reduce financial risk one must learn how to manage investment portfolio well. There are several techniques which firms \& investors can use for effective portfolio management.

Steps

\subsubsection{Be familiar with the different types of risk.}

Most financial risk can be categorized as either systematic or non-systematic. Systematic risk affects an entire economy and all of the businesses within it; an example of systematic risk would be losses due to a recession. Non-systematic risks are those that vary between companies or industries; these risks can be avoided completely through careful planning.

\subsubsection{Determine the level of risk associated with varied investments.}

Before reducing risk, one must understand how much risk he can expect from each type of investment. Stocks are some of the riskiest investments, but can also provide the highest return. Stocks carry no guarantee of repayment, and changing investor confidence can create market volatility, driving stock values down.

Bonds are less risky than stocks. Because they are debt instruments, repayment is guaranteed. The risk level of a bond is therefore dependent on the credit worthiness of the issuer; a company with shakier credit is more likely to default on a bond repayment.

Cash-equivalent investments, such as money market accounts, savings accounts, or government bonds are the least risky. These investments are also highly liquid, but they provide low returns.

\subsubsection{Determine the level of risk one is willing to shoulder.}

When deciding on an overall level of risk, one need to assess how he wants to use the money from his investments in the future.

If one is planning a big expenditure in the near future (such as a house or tuition), or one is retiring soon, one should aim for a relatively low-risk portfolio. This will help ensure that market volatility doesn't cause investments to lose a lot of value.

If investor is younger and investing for a long-term goal, more risk is appropriate. Long-term goals allow him to wait out stock price fluctuations and realize high returns over the long run.

\subsubsection{Reduce portfolio's risk level by allocating assets widely.}

The first key to lowering risk is to allocate money between different investment classes. Portfolio should include stocks, bonds, cash equivalents, and possibly other investments such as real estate. The proportion of these allocations will depend on the level of risk investor wants to shoulder overall.

Allocating assets widely hedges against the risk that certain asset classes will perform well while others perform poorly. For example, if many investors begin buying corporate stocks, stock prices will rise; however, those investors may be selling bonds to fund their stock purchases, causing bond prices to fall. Spreading investments between stocks and bonds will protect against the risk of either category performing poorly.

\subsubsection{Lower each asset type's risk through diversification.}

Diversifying portfolio means buying a single type of asset from many different companies. This hedges against the risk that a single company or industry will perform poorly or go bankrupt.

For example, if you buy stocks in 30 different companies, it is not likely that all 30 will perform poorly or go bankrupt at once, barring an economy-wide downturn. However, if you used the same amount of money to 
invest in only 1 company's stock, the company may perform poorly and drag your entire stock portfolio down with it.

\section{Study Of Financial Risk ManagementinHdfc (Ergo)General Insurance 3.1Risk Consulting Services}

Risk Management Services as an offering is along with insurance products and solutions is relatively new to the Indian General Insurance Industry. Risk Management has assumed importance with entry of private general insurance companies in the Indian market. Our company has been one of the pioneers in offering this service in the Indian Insurance Market to our Corporate Clientele.

The word 'management' can be defined in terms of organizing of activities and controlling the use of resources in such a manner as to achieve some desired objective. For an industrial or commercial firm the objective may be to maximize profits, to increase revenue, to increase net worth or combination of different objectives.

Risk Management as a subject concerned with the planning, arranging and controlling of activities and resources in order to minimize the impact of uncertain events. Risks arising out of uncertainty can be classified as production risks, marketing $\&$ distribution risks, financial risks, personnel risks and environmental risks.

\subsection{Several methods are used for handling of risks.}

\subsubsection{Avoidance -}

It is the most drastic way of handling of risks. It totally restricts to go by risk having certain activities which are considered to be 'risk prone'. For instance, if a factory uses some flammable substance for manufacturing of a product, one could think of not producing that product at all, so that the risk of fire is avoided.

\subsubsection{Risk Reduction -}

It covers all methods employed to reduce either the probability of loss producing events occurring, or potential size of losses that do occur. This is a more positive approach of looking at risks. For instance, if a factory has a spray painting section using flammable paints and thinners, it could look at switching to power coating.

\subsubsection{Risk Retention -}

Once the risks are identified and the costs of potential events are ascertained, the next stage is how to treat such risks. One option is to keep the risk to one self, which is to pay for them out of one's own resources when they occur. This is advised where the impact of risks are predictably small, measured accurately and do not threaten the business.

\subsubsection{Transfer -}

Alternative way for reduction of risk is to transfer the activities which creates the risks on to someone else instead of doing it oneself, for e.g. subcontracting of activities involving handling of highly flammable materials to third parties. However, the most important and practical form of risk transfer is 'insurance', whereby a professional risk carrier such as a Non-Life insurer is requested to carry the residual risk at a consideration, called the premium.

\section{Conclusion}

Financial risk management is not a contemporary issue. Financial risk management has been a challenge for as long as there have been markets and price fluctuations. Financial risks arise from an organization's exposure to financial markets, its transactions with others, and its reliance on processes, systems, and people. To understand financial risks, it is useful to consider the factors that affect financial prices and rates, including interest rates, exchange rates, and commodities prices.

The central conclusion of the paper is therefore that any system of regulation that is designed to protect against financial risk in needs to provide a high level of confidence that the firms which are supervised are able to survive any reasonable combination of stress shocks to their earnings with their capital sufficiently intact to ensure that they can continue in business long enough to allow appropriate remedial action to be taken either by the firm itself or by the regulator. 


\section{Reference}

[1] http://en.wikipedia.org/wiki/Risk

[2] http://www.investopedia.com/terms/f/financialrisk.asp\#axzz22Gu6FGX9

[3] http://books.google.co.in/books?id=X_zoNzVh-

QC\&pg=PT19\&lpg=PT19\&dq=finance+risk+management+selective+history\&source=bl\&ots=6qUYcRkJ4D\&sig=1aU7AoUGDs0F 3 smn_eHHzFuQ-J4\&hl=en\&sa=X\&ei=NQoPU-PuOIiJrgfh-

oGoCQ\&ved=0CD0Q6AEwAA\#v=onepage $\& \mathrm{q}=$ finance $\% 20$ risk $\% 20$ management $\% 20$ selective $\% 20$ history $\& \mathrm{f}=$ false

[4] http://fic.wharton.upenn.edu/fic/papers/99/9943.pdf

[5] http://kalyan-city.blogspot.in/2012/01/types-of-risk-systematic-and.html

[6] http://media.wiley.com/product_data/excerpt/67/04717061/0471706167.pdf

[7] http://www.wikihow.com/Reduce-Financial-Risk

[8] http://www.hdfcergo.com/Commercial/RiskConsultingServices.html

[9] Book- Security analysis and portfolio management- Pandian

[10] http://riskinstitute.ch/147320.htm 